\title{
Caffeinated Energy Drinks Boost Physical Performance In Several Sport Modalities: Should They Be Considered By Antidoping Authorities?
}

\author{
Juan Del Coso ${ }^{1^{*}}$, Beatriz Lara1, Francisco López-Muñoz ${ }^{2,3,4}$ \\ ${ }^{1}$ Exercise Physiology Laboratory, Camilo José Cela University, Madrid, Spain \\ ${ }^{2}$ Chair of Genomic Medicine and Faculty of Health Sciences, Camilo José Cela University, Madrid, Spain \\ ${ }^{3}$ Department of Biomedical Sciences (Pharmacology Area), Faculty of Medicine and Health Sciences, University of Alcalá, Madrid, Spain \\ ${ }^{4}$ Neuropsychopharmacology Unit, "Hospital 12 de Octubre" Research Institute, Madrid, Spain
}

Caffeine has been consumed by man for centuries although the manner of consumption has varied among different geographical zones, according to the source of caffeine present in natural foods (e.g., coffee, tea, mate, guaraná, kola, etc.). By the end of XIX century, John S. Pemberton created the first non-natural caffeinated-beverage that contained caffeine form the kola nut. The use of this beverage universally known as Coca-Cola- increased exponentially worldwide and favored the apparition of hundreds of commercial caffeinated drinks with similar characteristics. Although first energy drinks were marketed in Thailand in the 1970s, these drinks became widely popular when they were introduced in the European in the 1990s. Despite the commercial availability of numerous caffeinated beverages and foods, energy drinks have gained popularity in the last years, likely because they provide a higher dose of caffeine per serve.

Regardless of their name, energy drinks do not contain higher amounts of energy than other caffeinated drinks or sodas and this denomination seems more related to the "energizing" -e.g., stimulatingeffect that produce in the human body. Energy drinks typically contain $32 \mathrm{mg}$ of caffeine per $100 \mathrm{~mL}$ of product (while most caffeinated sodas contain $7 \mathrm{mg} / 100 \mathrm{~mL}$ of product) in addition to carbohydrates, taurine, glucoronolactone and B-group vitamins [1]. Among these ingredients, caffeine and carbohydrates are considered the most active constituents while the effectiveness of the remaining ingredients has not been scientifically tested with acute intake [2]. The amount of caffeine in a classic energy drink ( $250 \mathrm{~mL}=80 \mathrm{mg}$ of caffeine) is not very different from the amount of caffeine present in a cup of coffee or tea. However, energy drinks companies have recently increased the amount of drink per serve and these days, it can be easily found new $500 \mathrm{~mL}$-cans that rise the caffeine dosage per serve.

In a recent report of the European Food Safety Authority (EFSA) [3], it was certified that approximately $30 \%$ of adults were consumers of energy drinks, with $12 \%$ of them consuming energy drinks on $4-5$ days a week or more. However, the alarm of the EFSA was related to the high prevalence of energy drinks consumption in adolescent and children. Approximately $68 \%$ of adolescents with ages between 10 and 18 years were considered as regular consumers of caffeinated energy drinks while $18 \%$ of children between 3 and 10 years were reported ingestion of energy drinks in a regular manner. The massive use of these beverages requires exceptional scientific attention to determine the accuracy of the purported benefits associated to these drinks and possible side-effects associated to the intake of caffeinated energy drinks, especially in vulnerable populations. In fact, energy drinks have changed the manner of caffeine consumption in several settings, although it has specially affected the use of caffeine in sports.

Caffeine per se is the most consumed substance-with nonutritional- value in sports; a recent investigation determined the presence of caffeine in the post-competition urine of $74 \%$ of elite athletes of different sport disciplines [4]. This popularity is related to the removal of caffeine from the list of prohibited substances of the World Antidoping Agency in 2004 [5]. Due the well-recognized ergogenicity of caffeine and the accessibility low cost of these beverages, the intake of energy drinks has become the most popular manner of supplementing before exercise [6,7]. Caffeinated energy drinks have been found effective to significantly improve performance in several sport modalities. During simulated or real games, the pre-exercise ingestion of energy drinks, to obtain an individual dose of $3 \mathrm{mg}$ of caffeine per $\mathrm{kg}$ of body mass, increased the running distance covered at high- and/or sprint-intensity in male and female soccer players $[2,8]$ and the running distance covered at high-intensity in rugby players $[9,10]$. The ingestion of energy drinks has also improved jump performance in basketball players[11], the frequency of successful actions during volleyball games [12,13], the number of movements during a badminton game [14] and the distance covered at highintensity running and the number of sprints during a tennis match in junior players[15]. Interestingly, the ergogenicity of caffeinated energy drinks is not present when the amount of energy drink ingested only provides only $1 \mathrm{mg} / \mathrm{kg}$ of caffeine [16,17]. On the other hand, energy drinks intake in the sport setting might be accompanied by several negative side effects, including insomnia, nervousness and activeness, with similar incidences in both male and female athletes [18].

According to the World Antidoping Code [5], a substance -or method- will be included in the prohibited list whether its meets two of the following three criteria: 1) medical or other scientific evidence that the substance has the potential to enhance sport performance; 2) medical or other scientific evidence that the use of the substance represents a potential health risk to the athlete; 3) determination that the use of the substance or method violates the spirit of sport. Caffeinated energy drinks, when ingested in an amount to provide 3 $\mathrm{mg} / \mathrm{kg}$ of caffeine, have the potential to enhance sport performance in several modalities. On the other hand, this same dose of caffeine in the form of energy drink increases the prevalence of side effects associated to caffeine consumption. Health and antidoping authorities must weigh the positive and negative effects produced by the ingestion of caffeinated energy drinks to decide whether the use of these beverages should be controlled/limited in sports. To the opinion of these authors', the existing scientific information suggests that energy drinks do not fulfill the inclusion criteria to be included in the list of banned substances, because there is no medical or scientific proof that indicates that energy drinks as potential harmful for athletes, apart from increased insomnia

*Corresponding author: Juan Del Coso, Camilo José Cela University, C/ Castillo de Alarcón, 49, Villafranca del Castillo, 28692, Spain, Tel: 34+918 153 131; Fax 34+918 153 131; E-mail: jdelcoso@ucjc.edu

Received March 28, 2015; Accepted March 29, 2015; Published March 31, 2015

Citation: Del Coso J, Lara B, López-Muñoz F (2015) Caffeinated Energy Drinks Boost Physical Performance In Several Sport Modalities: Should They Be Considered By Antidoping Authorities? Clin Exp Pharmacol 5: e136. doi:10.4172/2161-1459.1000e136

Copyright: (c) 2015 Del Coso J, et al. This is an open-access article distributed under the terms of the Creative Commons Attribution License, which permits unrestricted use, distribution, and reproduction in any medium, provided the original author and source are credited. 
Citation: Del Coso J, Lara B, López-Muñoz F (2015) Caffeinated Energy Drinks Boost Physical Performance In Several Sport Modalities: Should They Be Considered By Antidoping Authorities? Clin Exp Pharmacol 5: e136. doi:10.4172/2161-1459.1000e136

and nervousness. However, antidoping authorities should track the trends of use and abuse of these beverages in sports.

\section{References}

1. Clauson KA Shields KM, McQueen CE, Persad N (2008) Safety issues associated with commercially available energy drinks. J Am Pharm Assoc 48: e55-63 e64-67.

2. Del Coso J, Muñoz-Fernández VE, Muñoz G, Fernández-Elías VE, Ortega JF, et al. (2012) Effects of a caffeine-containing energy drink on simulated soccer performance. PLoS One 7: e31380.

3. European Food and Safety Authority (2014) "Energy" drinks report.

4. Del Coso J, Muñoz G, Muñoz-Guerra J (2011) Prevalence of caffeine use in elite athletes following its removal from the World Anti-Doping Agency list of banned substances. Appl Physiol Nutr Metab 36: 555-561.

5. World Antidoping Web Site (2015)

6. Kristiansen M, Levy-Milne R, Barr S, Flint A (2005) Dietary supplement use by varsity athletes at a Canadian university. Int J Sport Nutr Exerc Metab 15 $195-210$

7. Hoffman JR (2010) Caffeine and energy drinks. Strength Conditioning J 32 15-20.

8. Lara B, González-Millán C, Salinero JJ, Abián-Vicen J, Areces F, et al. (2014) Caffeine-containing energy drink improves physical performance in female soccer players. Amino Acids 46: 1385-1392.

9. Del Coso J, Portillo J, Muñoz G, Abián-Vicen J, González-Millán C, et al (2013) Caffeine-containing energy drink improves sprint performance during an international rugby sevens competition. Amino Acids 44: 1511-1519.
10. Del Coso J, Ramirez JA, Muñoz G, González-Millán C, Muñoz V, et al. (2013) Caffeine-containing energy drink improves physical performance of elite rugby players during a simulated match. Appl Physiol Nutr Metab 38: 368-874.

11. Abián-Vicen J, Puente C, Salinero JJ, González-Millán C, Areces F, et al (2014) A caffeinated energy drink improves jump performance in adolescent basketball players. Amino Acids 46: 1333-1341.

12. Pérez-López A, Salinero JJ, Abián-Vicén J, Valadés D, Lara B, et al. (2015) Caffeinated energy drinks improve volleyball performance in elite female players. Med Sci Sports Exerc 47: 850-856.

13. Del Coso J, Pérez-López A, Abián-Vicén J, Salinero JJ, Lara B, et al. (2014) Enhancing physical performance in male volleyball players with a caffeinecontaining energy drink. Int J Sports Physiol Perform 9: 1013-1018.

14. Abian P, Del Coso J, Salinero JJ, Gallo-Salazar C, Areces F, et al. (2015) The ingestion of a caffeinated energy drink improves jump performance and activity patterns in elite badminton players. J Sports Sci 33: 1042-1050.

15. Gallo-Salazar C, Areces F, Abián-Vicen J, Lara B, Salinero JJ, et al. (2015) Caffeinated energy drinks enhance physical performance in elite junior tennis players. Int J Sports Physiol Perform 10: 305-310.

16. Astorino TA, Matera AJ, Basinger J, Evans M, Schurman T, et al. (2012) Effects of red bull energy drink on repeated sprint performance in women athletes. Amino Acids 42: 1803-1808.

17. Del Coso J, Salinero JJ, González-Millán C, Abián-Vicén J, Pérez-González $B$, et al. (2012) Dose response effects of a caffeine-containing energy drink on muscle performance: a repeated measures design. J Int Soc Sports Nutr 9: 21.

18. Salinero JJ, Lara B, Abian-Vicen J, González-Millán C, Areces F, et al. (2014) The use of energy drinks in sport: perceived ergogenicity and side effects in male and female athletes. Br J Nutr 112: 1494-1502. 